\title{
Morphological plasticity and variable spatial patterns in different populations of the red alga Rissoella verrucosa
}

\author{
Lisandro Benedetti-Cecchi*, Iacopo Bertocci, Stefano Vaselli, Elena Maggi \\ Dipartimento di Biologia, Università di Pisa, Via A. Volta 6, 56126 Pisa, Italy
}

\begin{abstract}
Understanding linkages between pattern and process across scales is one of the major issues in contemporary ecology. The extent to which our perception of the importance of scale is contingent on the specific ecological variable examined is still unknown. We compared patterns in size, biomass, density and cover of the red alga Rissoella verruculosa over multiple spatial scales (from 10s of $\mathrm{cm}$ to $10 \mathrm{~s}$ of $\mathrm{km}$ ) in the north-west Mediterranean and used a transplant experiment to investigate the underlying causes of variation. All response variables exhibited similar patterns of local variation. These included spatial heterogeneity across the vertical gradient of the shore and alongshore variability at scales of $10 \mathrm{~s}$ to $100 \mathrm{~s}$ of $\mathrm{m}$. In contrast, size, biomass and density of fronds, but not percentage cover, displayed significant large-scale variation. The reciprocal transplant experiment showed that the larger size attained by $R$. verruculosa at one location could be reversed when the alga was taken to another location about $70 \mathrm{~km}$ away, emphasizing large-scale differences in local processes rather than intrinsic differences between populations. It was found that morphological plasticity enabled this alga to display different patterns in size, biomass and density between locations. These results show that an analysis restricted to mean percentage cover would not have revealed the sensitivity of $R$. verruculosa to large-scale processes, emphasizing the advantages of simultaneously comparing variation in several attributes of populations to examine linkages between pattern and process across scales.
\end{abstract}

KEY WORDS: Morphological plasticity - Spatial scale $\cdot$ Rissoella verruculosa $\cdot$ Rocky shores · Transplant experiment

Resale or republication not permitted without written consent of the publisher

\section{INTRODUCTION}

Understanding the relationship between pattern and process is one of the main goals of ecological research. Ecologists are rapidly moving from the simple recognition that pattern results from complex interactions among variable processes, to a more thoughtful understanding of the hierarchical structure of causes and effects (Dayton \& Tegner 1984, Kotliar \& Wiens 1990, Menge \& Olson 1990, Levin 1992, Wiens et al. 1993, Schneider 1994, Wu \& Loucks 1995). Many ecological phenomena operate over distinct scales in space and time and most species display variability in ecological variables at some scales, but not at others (Holling
1992, Gaston \& McArdle 1993). This evidence suggests that the detection of spatial and temporal pattern can be revealing of the underlying causal forces (Underwood \& Chapman 1996).

Several studies have been undertaken in which the analysis of pattern at multiple scales is used to identify the processes that most likely affect the variables of interest (Farnsworth \& Ellison 1996, Åberg \& Pavia 1997, Connolly \& Roughgarden 1998, Hewitt et al. 1998, Sale 1998, Hughes et al. 1999, Jenkins et al. 2000, Crawley \& Harral 2001, Fowler-Walker \& Connell 2002). The logic underpinning this approach is that relevant processes will leave signatures in populations and assemblages by eliciting responses at spe- 
cific scales. These signals can then be traced back by examining how variability of targeted variables is distributed in space and time.

Although this approach can alert attention to potentially important processes, inferring causality solely from pattern analysis is untenable. Experimental tests of explanatory models are necessary to establish cause-effect relationships among ecological variables (Underwood 1990). This is generally appreciated by ecologists, although experimentation may be logistically difficult to conduct at large scales (Carpenter 1990, Carpenter et al. 1995).

Whilst suitable approaches for investigating pattern and process over multiple scales have been identified, some of the problems inherent in this type of research have not received sufficient attention. For example, organisms may display multiple responses depending on the biological variables considered. Most studies, however, have focused attention on density or other measures of abundance of populations, with the implicit assumption that these measures reflect the ability of a population to acquire resources, withstand disturbances and interact with other species. Although abundance (density) certainly affects all these properties of populations (Bertness \& Callaway 1994, Bertness \& Leonard 1997), focusing on abundance alone may not be enough to identify the full range of processes important for a particular organism. To what extent our perception of the importance of scale is contingent on the specific ecological variable examined remains largely unexplored.

In the present study, we explore the relationship between pattern and process in 2 populations of the red alga Rissoella verruculosa on 2 shores about $70 \mathrm{~km}$ apart in the north-west Mediterranean. This is an important species that strongly influences the structure of midshore assemblages through direct and indirect interactions (Benedetti-Cecchi 2000). Previous studies have revealed considerable small-scale spatial variation in mean percentage cover of the alga, but no difference between populations for this variable (Menconi et al. 1999, Benedetti-Cecchi 2001). Here, we investigate whether the same pattern can be recovered from the analysis of different attributes of the alga, namely size, biomass and density. This analysis revealed large variability between populations in all 3 response variables. We propose that large-scale differences could reflect either local differences in physical/biological features of the habitat, intrinsic differences between populations or a combination of these factors. We used a transplant experiment to test some of these propositions. The first proposition predicted that transplanted clumps of the alga would become similar in size to those of the receiving location, for both populations. The second proposition pre- dicted that transplanted clumps would remain similar in size to unmanipulated clumps of the donor population. The third proposition predicted that populations would respond dissimilarly to transplantation between locations.

The analysis of spatial pattern also revealed differences among heights of the shore in the size of fronds of Rissoella verruculosa that varied between populations. These inconsistencies might reflect intrinsic differences between populations of the alga, differences in physical and/or biological conditions between locations, or a combination of both factors. To examine these propositions, we compared the growth of fronds of $R$. verruculosa transplanted just beyond its upper and lower margins of distribution to that of fronds transplanted in the middle of a patch and to translocated and unmanipulated fronds. All comparisons were done as a function of the origin and destination of populations.

\section{MATERIALS AND METHODS}

Study system. The study was conducted at 2 locations in the Ligurian Sea: Calafuria (CF), a few kilometres south of Livorno $\left(43^{\circ} 30^{\prime} \mathrm{N}, 10^{\circ} 20^{\prime} \mathrm{E}\right.$ ) and Punta Bianca

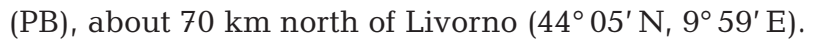
The substratum was sandstone at $\mathrm{CF}$, while schists and calcareous rocks occurred at PB. The northern locality is generally more productive than the southern one, with a mean $( \pm \mathrm{SE})$ chlorophyll concentration of $2.834 \pm$ $0.58 \mathrm{mg} \mathrm{m}^{-3}$ at $\mathrm{PB}$, compared to $0.625 \pm 0.04 \mathrm{mg} \mathrm{m}^{-3}$ at $\mathrm{CF}$ (data averaged over 4 yr of observation in the period 1998 to 2001: see www.santateresa.enea.it). Tidal ranges were narrow in the study region, as is typical for the Mediterranean, with an average amplitude of $25 \mathrm{~cm}$. However, changes in weather conditions and barometric pressure could be more important than the tidal regime in dictating the actual position of the sea level. As a consequence, organisms extended their range of distribution beyond the average limit of high tides (Menconi et al. 1999). All the activities described in this study were done on wave-exposed rocky shores.

The 2 locations supported qualitatively similar assemblages of algae and invertebrates. The top of the shore was usually dominated by the barnacle Chthamalus stellatus (Poli) and cyanobacteria (mostly Rivularia spp.), that were also present at mid-shore levels where assemblages were characterised by the foliose red alga Rissoella verruculosa (Bertolini) J. Agardh, filamentous algae such as Chaetomorpha aerea (Dillwyn) Kützing and Polysiphonia spp. and the brown crust Ralfsia verrucosa (Areschoug) J. Agardh. Lower levels of the shore were occupied by turf-forming algae (including several species of articulated coral- 
lines and filamentous and coarsely branched algae), the canopy-forming alga Cystoseira compressa (Esper) Gerloff et Nizzamuddin and the mussel Mytilus galloprovincialis Lamark. A major difference between the 2 locations was the dominance of turf-forming algae at $\mathrm{CF}$ that contrasted with the dominance of mussels at PB (Benedetti-Cecchi 2001). The most common grazers were the limpets Patella aspera Roding, P. coerulea Linnè and $P$. rustica Linnè. In addition to these general patterns of distribution, there was also considerable variation among patches of substratum within heights on the shore (Menconi et al. 1999, Benedetti-Cecchi 2000, 2001).

Rissoella verruculosa is a perennial alga endemic to the Mediterranean. Its life cycle is characterised by the alternation of 3 generations: the isomorphic gametophytic and sporophytic generations and the distinct carposporophytic generation (Fig. 1). The morphology of gametophytes and sporophytes is a coriaceous and elastic thallus, formed by red-brown to green-yellow upright fronds with indented edges, supported by a narrow stipe that arises from a perennial encrusting base. Upright fronds regenerate from the perennial basis in early winter and persist until the beginning of the warm season (June/July). The alga persists as an encrusting base during the summer (these crusts are almost invisible to the naked eye in the warm season). Detailed descriptions of these assemblages are reported elsewhere (Menconi et al. 1999, BenedettiCecchi 2001).

Patterns in size, biomass and density of fronds of Rissoella verruculosa. Spatial and temporal variation in size, biomass and density of fronds of $R$. verruculosa were examined with a multifactorial sampling design. Fronds were sampled on 3 occasions between February and June 1995, to test whether spatial patterns were consistent through time. At each time of sampling, 2 sites 10 s to 100 s of metres apart were examined at each location (CF and $\mathrm{PB})_{i}$ different sites were used at different times (a site was a stretch of coastline a few metres in length). Fronds were sampled at each of 3 heights on the shore at each site: close to the upper limit of patches of $R$. verruculosa, in the middle of these patches and close to the lower border, respectively. Three replicate quadrats of $20 \times 20 \mathrm{~cm}$ were placed randomly at each height in each site and measurements were taken in 3 sub-quadrats of $5 \times 5 \mathrm{~cm}$ randomly located within each quadrat. The length and width of the frond occupying the central portion of each sub-quadrat was measured with a plastic calliper (to the nearest $\mathrm{mm}$ ) directly in the field (width was measured approximately in the central part of the fronds). Subsequently, all fronds of $R$. verruculosa were removed with a paint scraper and taken to the laboratory in separate bags for each sub-quadrat. In the laboratory, the algae were weighed (wet mass to the nearest $0.001 \mathrm{~g}$ ) and the number of fronds was counted. Thus, the design consisted of 5 factors for each of the 3 response variables: (1) Time (3 levels), (2) Population (2 levels), (3) Height (3 levels), (4) Site (2 levels) and (5) Quadrat (3 levels), with $\mathrm{n}=3$ replicate measures in each quadrat. This sampling design encompassed a range of spatial scales comparable to that examined in analyses of patterns in percentage cover (Menconi et al. 1999, BenedettiCecchi 2001).

Reciprocal transplant experiment of Rissoella verruculosa. Hypotheses regarding determinants of largeand small-scale patterns of variation in size and biomass were tested with a reciprocal transplant experiment (Fig. 2). Chips of rock 5 to $10 \mathrm{~cm}^{2}$ in area and

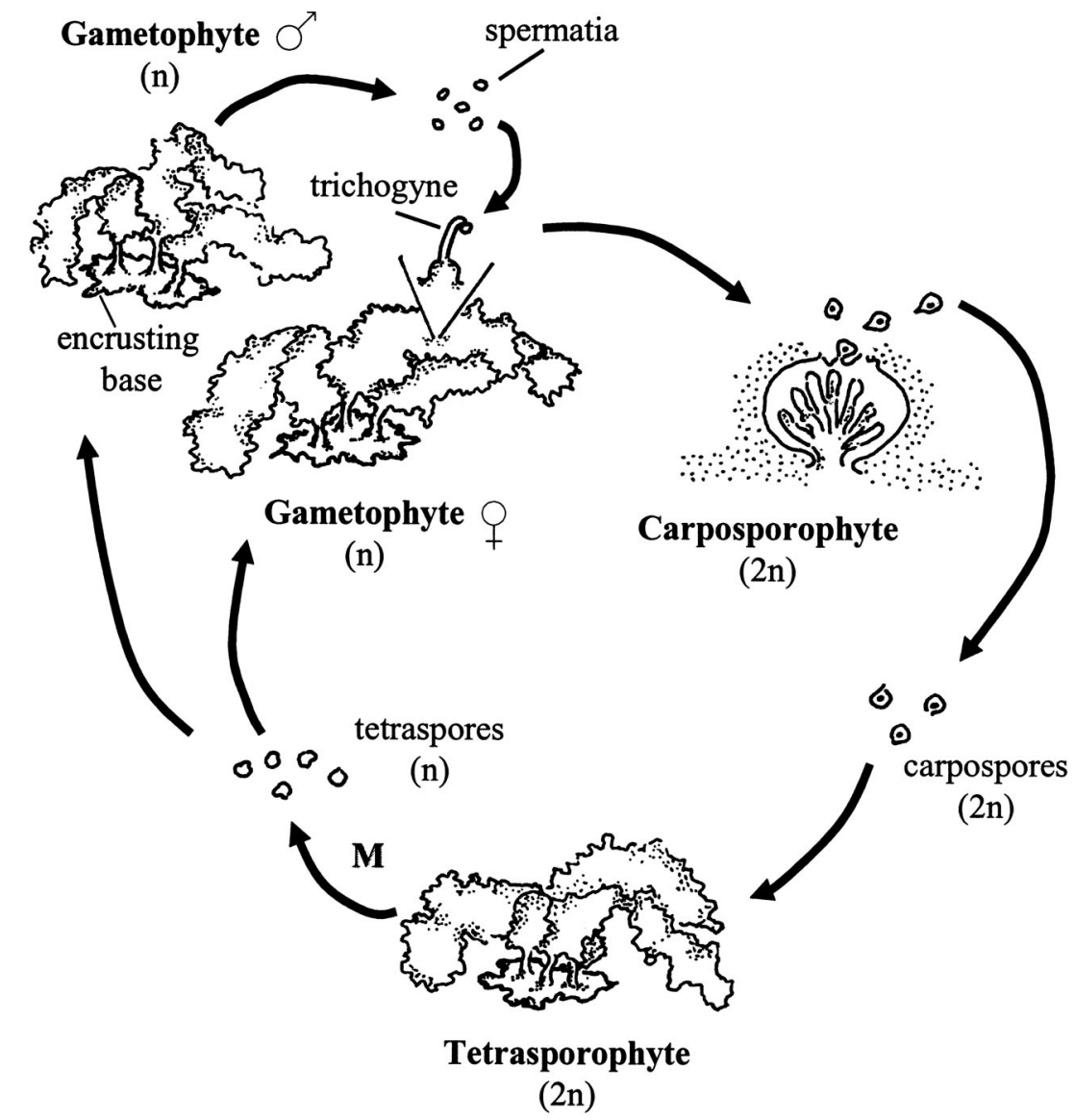

Fig. 1. Rissoella verruculosa. Diagrammatic representation of life-history 


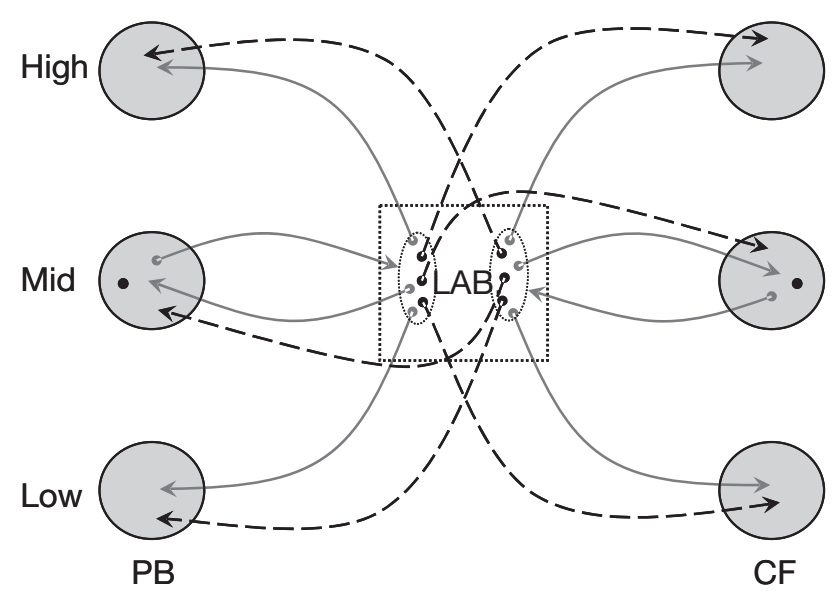

Fig. 2. Rissoella verruculosa. Schematic representation of the reciprocal transplant experiment. (-): disturbed and translocated treatments that were taken back to the original location; $(---)$ : transplanted treatments; PB: Punta Bianca; CF: Calafuria; LAB: the laboratory in Pisa; High, Mid and Low refer to highshore, midshore and lowshore positions on the coasts, respectively, (•): unmanipulated controls at midshore levels

covered by the encrusting base of $R$. verruculosa were collected from midshore levels at $\mathrm{CF}$ and $\mathrm{PB}$ and randomly assigned to levels of experimental factors in December 1995. The experimental design included the following factors: (1) Treatment (3 levels, transplanted, translocated and unmoved chips), (2) Destination, the location where fronds were allowed to grow (2 levels, CF and PB) (the analysis was also repeated by Origin, see 'Statistical analyses'), (3) Height, the vertical position with respect to patches of $R$. verruculosa where chips were placed (3 levels, centre of patches and about $10 \mathrm{~cm}$ in vertical extent above and below patches, respectively) and (4) Site (2 replicated sites within each combination of levels of the other factors), with $\mathrm{n}=4$ replicate chips in each site.

The first treatment consisted of transplanted chips that were collected at one location and moved to the other location. Because it was not possible to do this within a single day, chips were collected, kept for 1 night in moist conditions in the laboratory and then transplanted to the appropriate position in the new location the following day. There are several possible artefacts associated with this manipulation, including effects of collecting and transporting chips, leaving them for 1 night in the laboratory, moving to a new place (regardless of any possible effect of height on the shore or location) and fixing to a new position. We did not have enough resources to control for every single artefact (see Chapman 1986 for an appropriate design to separate the effects of disturbing and moving experimental units). Instead, we focused on the net effect of any possible combination of artefacts. This was achieved with the second treatment, consisting of the translocation of chips that were kept for 1 night in the laboratory before being returned to their source location, but not in the original sites. This treatment controlled for the effects of transportation (including staying overnight in the laboratory) and movement from one place on the shore to another. Previous studies indicated that chiselling chips from the substratum and fastening them into chiselled depressions of the rock with epoxy putty (Subcoat-S, Veneziani) did not introduce detectable artefacts (Benedetti-Cecchi 2000). These same techniques were used to manipulate chips in the present study. Finally, the third treatment included unmanipulated controls. The size of individual chips was not measured, but the random allocation of chips to treatments should have avoided significant bias, as indicated by previous experiments (BenedettiCecchi 2000).

In June 1996 all chips were collected and brought to the laboratory, where the length and the width of the largest frond on each of these units was measured to the nearest $\mathrm{mm}$ with a plastic calliper. The biomass of the largest frond was also measured as wet weight (to the nearest $0.001 \mathrm{~g}$ ). The fronds occurring on the chips were those produced in the previous 6 mo, as chips were covered by the encrusting base of Rissoella verruculosa at the beginning of the experiment. Because loss of biomass due to storms and grazers is likely to be minimal for this species (Benedetti-Cecchi 2000) and because the experiment started after the reproductive period of the alga so that no new individuals recruited on the chips, biomass was used as a measure of the productivity of $R$. verruculosa. By measuring the size of the largest fronds, we restricted our hypotheses to the maximum size achievable by upright fronds in the various experimental conditions.

Statistical analyses. Data were analyzed with mixed models of analysis of variance. Treatment, Population, Destination and Height were treated as fixed effects in analyses, whereas Site, Time and Quadrat were random sources of variation. Population was considered fixed because hypotheses were specific for the populations of Rissoella verruculosa of CF and PB. Thus, results apply only to these populations and not to others that might have occurred elsewhere in the northwest Mediterranean. A 5-factor design was used to analyze data on spatial and temporal variability in size, biomass and density of fronds. Time, Population and Height were crossed factors, Site was nested in the Time $\times$ Population interaction and crossed with Height, whereas Quadrat was nested in the Height $\times$ Site (Time $\times$ Population) term.

Data from the reciprocal transplant experiment were analyzed with a 4 -factor design. Two types of analysis 
were performed, 1 by Destination and 1 by Origin (Crowe \& Underwood 1999, Underwood et al. 2004). If differences in size of Rissoella verruculosa between $\mathrm{PB}$ and CF reflected an intrinsic property of populations, then one would predict that transplanted fronds will continue to grow like fronds in the native location and will differ from those in the receiving location. This effect would be detected by a Treatment $\times$ Destination interaction in the analysis. If, in contrast, growth is determined by the characteristics of the habitat, then the analysis would detect a main effect of Destination. The opposite is expected from analyses based on Origin. In this case intrinsic differences between populations would elicit a significant effect of Origin, whilst the effect of habitat would be detected by a significant Treatment $\times$ Origin interaction. Of course intermediate scenarios are also possible, such as the case in which only 1 population responds to transplantation. This pattern would be detected by significant Treatment $\times$ Destination and Treatment $\times$ Origin interactions.

These hypotheses were tested in a single analysis that included the effect of height on the shore. This requires some justification. Because observations indicated different patterns of cross-shore variation in size of Rissoella verruculosa between $\mathrm{PB}$ and $\mathrm{CF}$, the relative importance of habitat vs. intrinsic differences between populations in determining the size of the alga could differ in relation to height on the shore. These effects would be detected by a significant interaction between Height and any of the relevant terms useful to discriminate among effects of habitat and population. In addition, because natural variability was large at the 2 locations, including data from different heights of the shore in a single analysis increased the statistical power of the relevant tests.

Treatment, Destination (or Origin) and Height were crossed factors and Site was nested in the Treatment $x$ Destination (or Origin) $\times$ Height interaction. Denominators for $F$ ratios were derived from expected mean squares for each model of analysis (Winer et al. 1991, Underwood 1997). Cochran's C-test was used to examine whether variances were homogeneous across levels of experimental factors. When the assumption of homogeneity of variances was violated, data were transformed and the assumption was checked again. Analyses were done on transformed data if the transformation effectively removed heterogeneity, otherwise untransformed data were analysed. When appropriate, SNK tests were performed for a posteriori multiple comparisons of the means. All tests were done at $\alpha=0.05$.

\section{RESULTS}

\section{Patterns in size, biomass and density of fronds of Rissoella verruculosa}

Length of fronds of Rissoella verruculosa varied interactively with Population and Height on the shore (significant Population $\times$ Height interaction in Table 1 ;

Table 1. Rissoella verruculosa. Analysis of variance on patterns of spatial and temporal variation in size

\begin{tabular}{|c|c|c|c|c|c|c|c|c|c|c|c|c|c|}
\hline \multirow{2}{*}{ Source of variation } & \multirow[t]{2}{*}{$\mathrm{df}$} & \multicolumn{3}{|c|}{ _ Length } & \multicolumn{3}{|c|}{ - Width } & \multicolumn{3}{|c|}{ Biomass } & \multicolumn{3}{|c|}{ - Density } \\
\hline & & MS & $F$ & $\mathrm{p}$ & MS & $F$ & $\mathrm{p}$ & MS & $F$ & $\mathrm{p}$ & MS & $F$ & $\mathrm{p}$ \\
\hline Time & 2 & 22370 & 3.1 & $>0.1$ & 6.594 & 8.7 & $<0.05$ & 0.898 & 2.2 & $>0.1$ & 3.248 & 10.0 & $<0.05$ \\
\hline Population & 1 & 58968 & 27.8 & $<0.05$ & 67.663 & 481.3 & $<0.005$ & 3.715 & 8.9 & $>0.05$ & 20.858 & 28.5 & $<0.05$ \\
\hline Height & 2 & 24514 & 16.9 & $<0.05$ & 8.699 & 18.1 & $<0.01$ & 1.346 & 6.1 & $>0.05$ & 0.625 & 1.4 & $>0.3$ \\
\hline Time $\times$ Population & 2 & 2121 & 0.3 & $>0.7$ & 0.141 & 0.2 & $>0.8$ & 0.419 & 1.0 & $>0.4$ & 0.733 & 2.3 & $>0.1$ \\
\hline Time $\times$ Height & 4 & 1455 & 1.0 & $>0.4$ & 0.480 & 0.8 & $>0.5$ & 0.222 & 2.0 & $>0.1$ & 0.443 & 0.5 & $>0.7$ \\
\hline Population $\times$ Height & 2 & $7237^{a}$ & 5.8 & $<0.05$ & 0.561 & 0.6 & $>0.6$ & $0.604^{\mathrm{a}}$ & 5.3 & $<0.05$ & 2.281 & 8.4 & $<0.05$ \\
\hline Time $\times$ Population $\times$ Height & 4 & 1252 & 0.9 & $>0.5$ & 1.002 & 1.7 & $>0.2$ & 0.101 & 0.9 & $>0.4$ & 0.272 & 0.3 & $>0.8$ \\
\hline Site $($ Time $\times$ Population) & 6 & 7185 & 16.7 & $<0.001$ & 0.757 & 2.8 & $<0.05$ & 0.411 & 12.4 & $<0.001$ & 0.324 & 0.8 & $>0.6$ \\
\hline $\begin{array}{l}\text { Height } \times \text { Site }(\text { Time } \times \\
\text { Population) }\end{array}$ & 12 & 1479 & 3.5 & $<0.001$ & 0.605 & 2.3 & $<0.05$ & 0.113 & 3.4 & $<0.001$ & 0.820 & 1.9 & $<0.05$ \\
\hline $\begin{array}{l}\text { Quadrat }(\text { Height } \times \text { Site } \\
(\text { Time } \times \text { Population) })\end{array}$ & 72 & 429 & 3.6 & $<0.001$ & 0.268 & 2.9 & $<0.001$ & 0.033 & 2.8 & $<0.001$ & 0.425 & 2.3 & $<0.001$ \\
\hline Residual & 216 & 119 & & & 0.093 & & & 0.012 & & & 0.184 & & \\
\hline $\begin{array}{l}\text { Cochran's } C \text {-test } \\
\text { Transformation }\end{array}$ & & $C=0.0$ & $\begin{array}{l}946, p \\
\text { none }\end{array}$ & $>0.05$ & $C=0.0$ & $\begin{array}{l}0652, p \\
\ln (x+1)\end{array}$ & $>0.05$ & $C=0.1$ & $\begin{array}{l}\text { 363, p } \\
\text { none }\end{array}$ & $>0.05$ & $C=0.0$ & $\begin{array}{l}566, p \\
\text { none }\end{array}$ & $>0.05$ \\
\hline
\end{tabular}



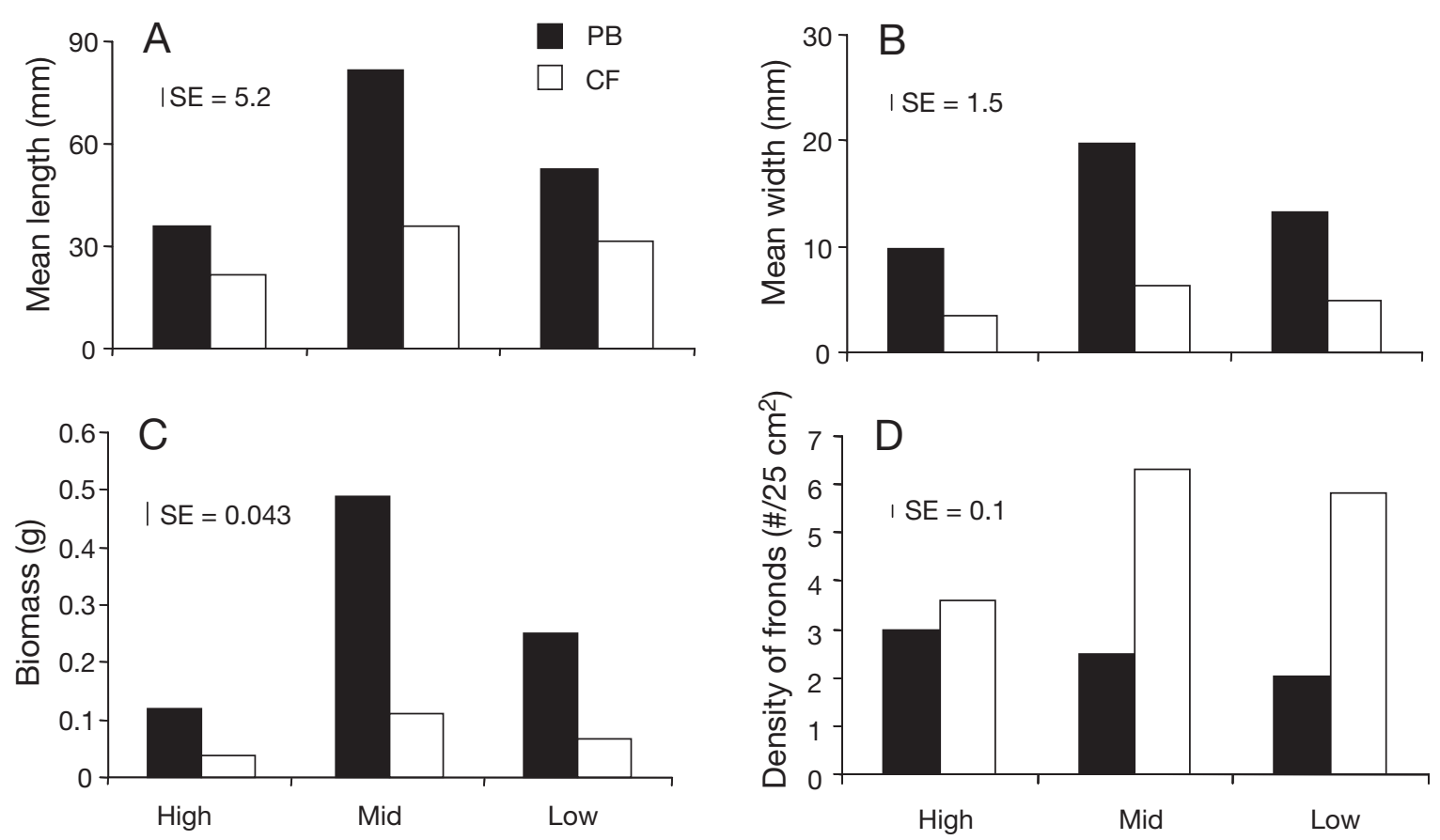

Fig. 3. Rissoella verruculosa. Patterns in (A) length, (B) width, (C) biomass and (D) density of fronds at each of 3 positions on the shore at Punta Bianca (PB) and Calafuria (CF). Error bars are the square roots of ratios between the Mean Square of the Time $\times$ Population $\times$ Height interaction in Table 1 (the natural denominator for testing the Population $\times$ Height interaction) and the number of observations used to calculate treatment means $(n=54)$. This approach provided a pooled estimate of the variation among subgroups (Winer et al. 1991, Underwood 1997)

Fig. 4A). There was no significant difference between the 2 populations when fronds were sampled close to the upper margin of distribution of the alga, whereas $R$. verruculosa at $\mathrm{PB}$ had significantly longer fronds than CF both in the centre of patches and close to the lower margin (Fig. 3A, SNK tests). Furthermore, there was no variation in length across heights of the shore

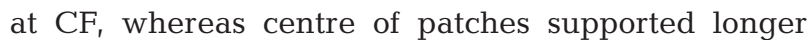
fronds at $\mathrm{PB}$, followed by the lowshore margin that had significantly larger fronds than the upper margin (SNK tests).

The analysis of width across heights of the shore revealed a more general pattern, with significantly wider fronds in the centre of patches compared to the upper and lower margins that did not differ significantly (Fig. 3B, SNK tests).

Cross-shore variation in size of fronds also varied at the scale of site, as indicated by the significant Height $\times$ Site (Time $\times$ Population) interactions and at the scale of Quadrat, both for length and width (Table 1).

Patterns in biomass resembled those in mean length, with a significant Population $\times$ Height interaction (Fig. 3C, Table 1). Fronds from the centre of patches and from lower margins had larger values of biomass at $\mathrm{PB}$ than $\mathrm{CF}$, whereas no difference between populations occurred for upper margins (SNK tests). At PB, upper margins had significantly lower biomass of Ris- soella verruculosa compared to the other positions that did not differ significantly. In contrast, mean biomass did not differ significantly across heights on the shore at CF (SNK tests). Cross-shore variation in biomass was very variable at the scale of site (Table 1).

Patterns in mean number of fronds per sub-quadrat were opposite to those described for biomass (Fig. 3D, Table 1). Density was significantly larger at CF than PB in the centre of patches and towards the lower margins of distribution of Rissoella verruculosa, whereas no difference occurred at the upper margins. At $C F$, upper margins also had significantly lower densities of $R$. verruculosa compared to the other positions that did not differ significantly. In contrast, mean density did not differ significantly across heights on the shore at PB (SNK tests). Patterns of cross-shore variation in density differed at the scale of site, as illustrated by the significance of the Height $\times$ Site (Time $\times$ Population) interaction (Table 1).

\section{Reciprocal transplant experiment of Rissoella verruculosa}

The analysis of the reciprocal transplant experiment with data organized by Destination revealed significant Treatment $\times$ Destination and Destination $\times$ Height 
interactions on mean length of fronds (Fig. 4, Table 2). Rissoella verruculosa originating from PB and transplanted to CF developed fronds that did not differ significantly from those of the receiving location. In contrast, fronds that were taken from CF to PB maintained the same size as those in the source location, while they differed significantly from those in the receiving location (Fig. 4A, SNK tests).

There were opposite patterns of cross-shore variation between $\mathrm{CF}$ and $\mathrm{PB}$ in mean length of fronds (Fig. 4B). Though SNK tests could not rank means consistently across treatments, they detected a significant difference between locations high on the shore. Lack of a significant Treatment $\times$ Destination $\times$ Height interaction indicated a similar response of fronds to transplantation beyond the natural boundaries of vertical distribution, regardless of origin and destination (Table 2).

Patterns in width of fronds were similar to those described for mean length (Fig. 4C, Table 2). A significant Treatment $\times$ Destination interaction resulted from a differential response of the 2 populations of Rissoella verruculosa to transplantation. Chips transplanted from CF to PB developed fronds that were significantly narrower than those of the receiving location and that did not differ from those of the source location. In contrast, all fronds had similar width at $\mathrm{CF}$, indicating that transplanted chips had narrower fronds than those of the source location (SNK tests). In contrast to patterns in length, mean width did not differ among heights on the shore. Both length and width exhibited significant alongshore variability at the scale of site (Table 2).

For biomass of fronds, the analysis detected a significant Treatment $\times$ Destination interaction, similar to what was observed for the other response variables (Fig. 5A, Table 2). This interaction originated because chips taken from CF to PB developed fronds that were more similar to those of the native location, whereas
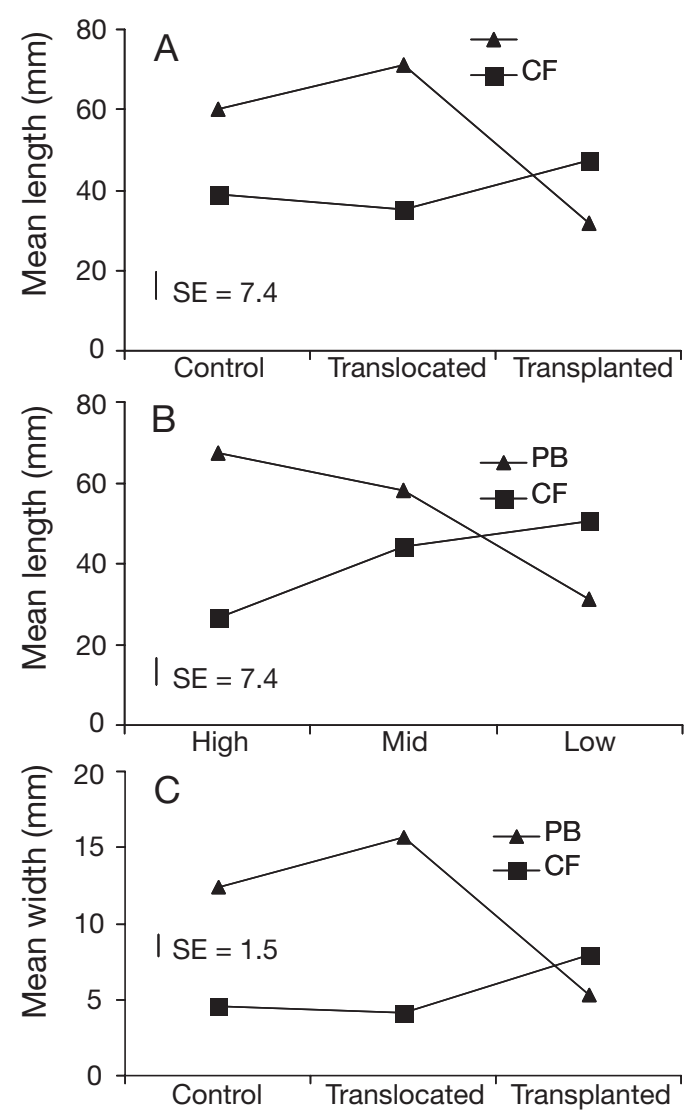

Fig. 4. Rissoella verruculosa. Results of the reciprocal transplant experiment with data organized by Destination. Panels illustrate patterns in mean length of fronds (A) for different treatment conditions and (B) in relation to position on the shore, and (C) patterns in mean width of fronds for different treatment conditions, at PB and CF. Error bars are the square roots of the ratios between the Mean Square of the Site (Treatment $\times$ Destination $\times$ Height) term in Table 2 (the natural denominator for testing both the Treatment $\times$ Destination and Destination $\times$ Height interactions) and the number of observations used to calculate treatment means $(n=18)$. See

legend of Fig. 3 for further details and abbreviations

Table 2. Rissoella verruculosa. Analysis of the reciprocal transplant experiment with data organized by Destination

\begin{tabular}{|c|c|c|c|c|c|c|c|c|c|c|}
\hline \multirow[t]{2}{*}{ Source of variation } & \multirow[t]{2}{*}{ df } & \multicolumn{3}{|c|}{ Length - } & \multicolumn{3}{|c|}{ Width- } & \multicolumn{3}{|c|}{ Biomass } \\
\hline & & MS & $F$ & $\mathrm{p}$ & MS & $F$ & $\mathrm{p}$ & MS & $F$ & $\mathrm{p}$ \\
\hline Treatment & 2 & 2326 & 1.8 & $>0.1$ & 132.2 & 2.3 & $>0.1$ & 0.100 & 2.9 & $>0.05$ \\
\hline Destination & 1 & 6765 & 5.2 & $<0.05$ & 1141.9 & 20.0 & $<0.001$ & 0.614 & 17.4 & $<0.001$ \\
\hline Height & 2 & 627 & 0.5 & $>0.6$ & 50.6 & 0.9 & $>0.4$ & 0.031 & 0.9 & $>0.4$ \\
\hline Treatment $\times$ Destination & 2 & 8459 & 6.4 & $<0.01$ & 651.0 & 11.4 & $<0.001$ & 0.261 & 7.4 & $<0.01$ \\
\hline Treatment $\times$ Height & 4 & 2670 & 2.0 & $>0.1$ & 76.5 & 1.3 & $>0.2$ & 0.078 & 2.2 & $>0.1$ \\
\hline Destination $\times$ Height & 2 & 8924 & 6.8 & $<0.01$ & 178.0 & 3.1 & $>0.05$ & 0.199 & 5.6 & $<0.05$ \\
\hline Treatment $\times$ Destination $\times$ Height & 4 & 1338 & 1.0 & $>0.4$ & 37.0 & 0.7 & $>0.6$ & 0.049 & 1.4 & $>0.2$ \\
\hline Site $($ Treatment $\times$ Destination $\times$ Height) & 18 & 1314 & 5.4 & $<0.001$ & 57.2 & 7.1 & $<0.001$ & 0.035 & 4.8 & $<0.001$ \\
\hline Residual & 108 & 243 & & & 8.0 & & & 0.007 & & \\
\hline $\begin{array}{l}\text { Cochran's } C \text {-test } \\
\text { Transformation }\end{array}$ & & \multicolumn{3}{|c|}{$\begin{array}{c}C=0.1274, \mathrm{p}>0.05 \\
\text { none }\end{array}$} & \multicolumn{3}{|c|}{$\begin{array}{c}C=0.1455, \mathrm{p}>0.05 \\
\text { none }\end{array}$} & \multicolumn{3}{|c|}{$\begin{array}{c}C=0.1830, \mathrm{p}<0.05 \\
\text { none }\end{array}$} \\
\hline
\end{tabular}




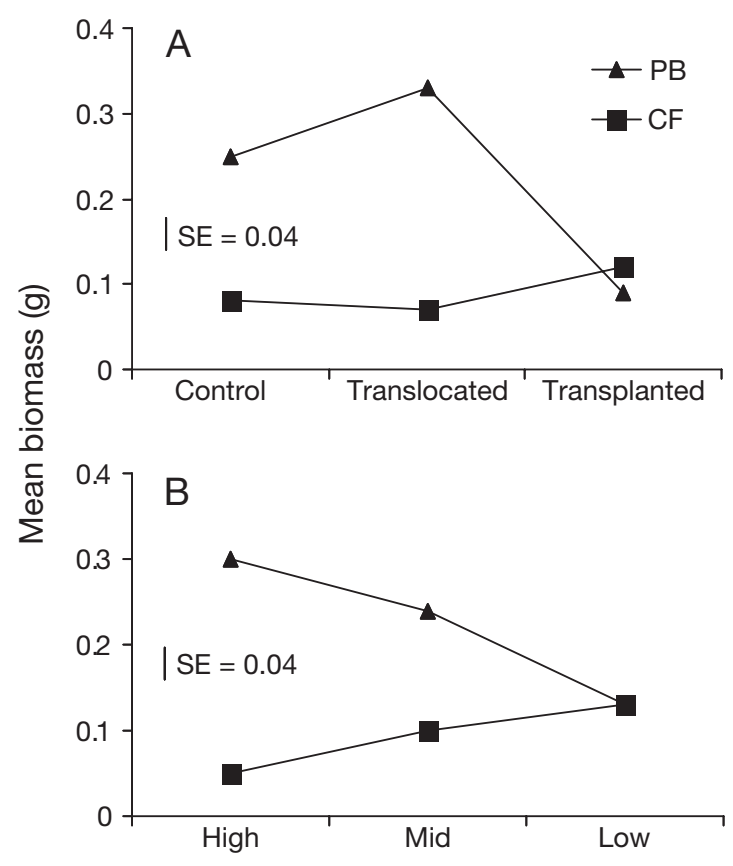

Fig. 5. Rissoella verruculosa. Results of the reciprocal transplant experiment with data organized by Destination. Panels illustrate mean biomass of fronds in (A) different treatment conditions and (B) in relation to position on the shore at $\mathrm{PB}$ and CF. Error bars are calculated as in Fig. 4 and abbreviations are as in Fig. 3

the opposite occurred for fronds originating at PB and transplanted to $\mathrm{CF}$, which were more similar to those of the receiving location (SNK tests). Although the assumption of homogeneity of variances was not met (Table 2), this test would still be significant at the more conservative level of $\alpha=0.01$. The analysis on biomass also detected a significant Destination $\times$ Height interaction (Table 2), showing opposite patterns of crossshore variation in biomass between the 2 locations (Fig. 5B). SNK tests within these interactions revealed that biomass was significantly larger highshore than lowshore at $\mathrm{PB}$, with the midshore position being inconsistently ranked between the two. In contrast, biomass did not change significantly with height on the shore at CF. These tests also indicated significantly larger values of biomass at $\mathrm{PB}$ than $\mathrm{CF}$ for highshore and midshore positions, but not lower on the shore. Tests would be no longer significant at $\alpha=0.01$.

The analysis by Origin on mean length of fronds did not detect any effect of Treatment, either as a main term or in interaction with other factors (Table 3). The analysis only revealed a significant Origin $\times$ Height interaction reflecting larger fronds of Rissoella verruculosa at PB than at CF high on the shore, whilst mean size did not differ between locations when fronds were placed at midshore or lowshore (Table 3, SNK tests). This is the same as the pattern detected with analysis by Destination. Significant Treatment $\times$ Origin interactions were detected for mean width and mean biomass of fronds (Table 3, Fig. 6). Both response variables were significantly larger at PB than at CF for Control and Translocated treatments, whilst the 2 populations were no longer distinguishable when transplanted to the other location (SNK tests). This pattern occurred because fronds originating from $\mathrm{PB}$ and transplanted to $\mathrm{CF}$ became similar to those of the receiving location, whilst transplanted fronds originating from $\mathrm{CF}$ remained similar to those of the native location.

Because chips were small in size, several of them had a limited number of fronds (2 to 4 ), regardless of their origin. For this reason density of fronds was not included in these analyses.

\section{DISCUSSION}

The combination of sampling and experimental analyses used in this study revealed that large-scale patterns of variation of Rissoella verruculosa were not consistent among response variables and that the 2

Table 3. Rissoella verruculosa. Analysis of the reciprocal transplant experiment with data organized by Origin

\begin{tabular}{|c|c|c|c|c|c|c|c|c|c|c|}
\hline \multirow[t]{2}{*}{ Source of variation } & \multirow[t]{2}{*}{$\mathrm{df}$} & \multicolumn{3}{|c|}{ - Length } & \multicolumn{3}{|c|}{ Width } & \multicolumn{3}{|c|}{ - Biomass } \\
\hline & & MS & $F$ & $\mathrm{p}$ & MS & $F$ & $\mathrm{p}$ & MS & $F$ & $\mathrm{p}$ \\
\hline Treatment & 2 & 2326 & 1.8 & $>0.19$ & 132.2 & 2.3 & $>0.12$ & 0.100 & 2.8 & $>0.05$ \\
\hline Origin & 1 & 21098 & 16.1 & $<0.001$ & 1947.0 & 34.0 & $<0.001$ & 0.827 & 23.4 & $<0.001$ \\
\hline Height & 2 & 627 & 0.5 & $>0.6$ & 50.6 & 0.9 & $>0.4$ & 0.031 & 0.9 & $>0.4$ \\
\hline Treatment $\times$ Origin & 2 & 1293 & 1.0 & $>0.35$ & 248.5 & 4.3 & $<0.05$ & 0.154 & 4.4 & $<0.05$ \\
\hline Treatment $\times$ Height & 4 & 2670 & 2.0 & $>0.1$ & 76.5 & 1.3 & $>0.25$ & 0.078 & 2.2 & $>0.1$ \\
\hline Origin $\times$ Height & 2 & 4784 & 3.6 & $<0.05$ & 112.3 & 2.0 & $>0.15$ & 0.145 & 4.1 & $<0.05$ \\
\hline Treatment $\times$ Origin $\times$ Height & 4 & 3408 & 2.6 & $>0.05$ & 69.9 & 1.2 & $>0.3$ & 0.076 & 2.2 & $>0.1$ \\
\hline Site $($ Treatment $\times$ Origin $\times$ Height $)$ & 18 & 1314 & 5.4 & $<0.001$ & 57.2 & 7.1 & $<0.001$ & 0.035 & 4.8 & $<0.001$ \\
\hline Residual & 108 & 243 & & & 8.0 & & & 0.007 & & \\
\hline $\begin{array}{l}\text { Cochran's } C \text {-test } \\
\text { Transformation }\end{array}$ & & \multicolumn{3}{|c|}{$\begin{array}{c}C=0.1274, \mathrm{p}>0.05 \\
\text { none }\end{array}$} & \multicolumn{3}{|c|}{$\begin{array}{c}C=0.1455, \mathrm{p}>0.05 \\
\text { none }\end{array}$} & \multicolumn{3}{|c|}{$\begin{array}{c}C=0.1830, \mathrm{p}<0.05 \\
\text { none }\end{array}$} \\
\hline
\end{tabular}



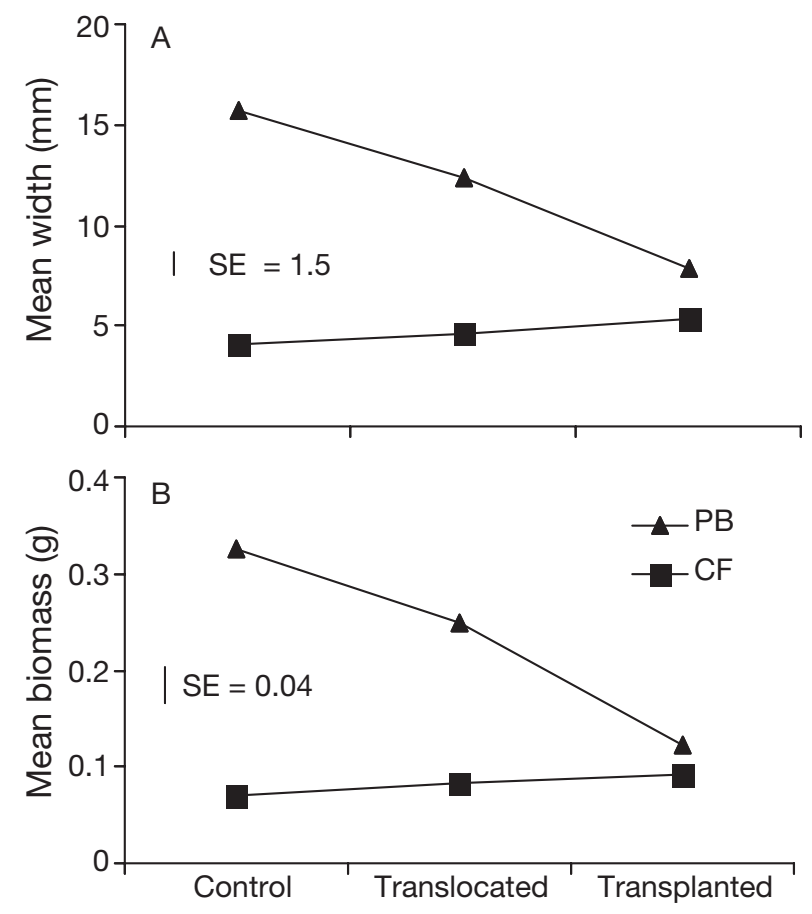

Fig. 6. Rissoella verruculosa. Results of the reciprocal transplant experiment with data organized by Origin. Panels illustrate patterns in (A) mean width and (B) mean biomass of fronds in different treatment conditions at PB and CF. Error bars are calculated as in Fig. 4 and abbreviations are as in Fig. 3

populations differed in their ability to respond to largescale changes in environmental conditions. These effects were evident on attributes such as size, biomass and density of the alga, but not on percentage cover, as indicated by previous studies (Menconi et al. 1999, Benedetti-Cecchi 2001). Small-scale effects, in contrast, were similar among variables.

The quantitative description of spatial and temporal pattern in populations is important for identifying the relevant scales of variation over which causal processes need to be understood. Detection of pattern is therefore a necessary step before manipulative studies of causal processes can be undertaken (Underwood \& Chapman 1996). Although the relationship between pattern and process is a central theme in ecological research, the question of whether this relationship remains unchanged when different attributes of populations are examined remains largely unexplored. Most of our current understanding of the linkages between pattern and process over multiple scales comes from studies that have focused on abundance of populations. Abundance is certainly a key response variable to focus on, as it integrates many processes over space and time, but the extent to which abundance alone can capture the full range of processes that are relevant to a population is unclear.
By integrating the results of the present study with those of previous analyses (Menconi et al. 1999, Benedetti-Cecchi 2001), we compared patterns of variation of several attributes of Rissoella verruculosa at various spatial scales. We found clear differences between $\mathrm{PB}$ and $\mathrm{CF}$ in size, biomass and density, whereas large-scale variation in mean cover was negligible for this alga. Thus, the perception of the importance of large-scale processes from an analysis of spatial pattern was contingent on the particular response variables examined. An analysis of spatial pattern focusing solely on mean cover would have provided no evidence of the importance of variation between populations.

Why did size and biomass of Rissoella verruculosa differ so markedly between $\mathrm{PB}$ and $\mathrm{CF}$ ? The reciprocal transplant experiment tested whether large-scale patterns in these variables reflected intrinsic differences between the 2 populations, local differences in physical/biological features of the habitat or a combination of these factors. $R$. verruculosa taken from $\mathrm{PB}$ to $\mathrm{CF}$ attained a smaller size compared to clumps growing in the native location, being more similar to the population of the receiving location. In contrast, $R$. verruculosa that was transplanted from CF to PB developed fronds that were similar in size to those growing in the native location. This asymmetrical response to transplantation provided support for the third explanation (i.e. combined effects of habitat and characteristics of the population), but it made interpretation of results difficult. It is possible that the time required for $R$. verruculosa to respond to a change in environmental conditions depended on the direction of the response. The experiment might have run for a sufficient period of time to elicit a reduction in growth of $R$. verruculosa that was transplanted from $\mathrm{PB}$ to $\mathrm{CF}$, but not long enough to observe a positive effect on clumps that from $\mathrm{CF}$ were transplanted to $\mathrm{PB}$. Alternatively, it is possible that the population of $\mathrm{PB}$ was characterized by a larger degree of morphological plasticity than that of $\mathrm{CF}$, regardless of the direction of the effect. Distinguishing between these 2 alternatives would require additional experiments in which the 2 populations are transplanted simultaneously to a set of unfamiliar localities under a wide range of environmental conditions.

Despite difficulties in interpretation, 2 lines of evidence suggest that differences in physical and/or biological conditions between $\mathrm{PB}$ and $\mathrm{CF}$ were more important than intrinsic differences between populations in dictating the outcome of the experiment. First, this interpretation was reinforced by the evidence that when Rissoella verruculosa was transplanted outside its natural limits of vertical distribution, patterns of cross-shore variation in size were in opposite direction 
at the 2 localities (as indicated by the significant Destination $\times$ Height and Origin $\times$ Height interactions in Tables $2 \& 3$, respectively), whereas differences in size between populations were not evident (Treatment $\times$ Destination $\times$ Height and Treatment $\times$ Origin $\times$ Height interactions were never significant). This result indicates that the 2 populations responded in a similar fashion when transplanted to unfamiliar habitats at each location and that there were overall differences between $\mathrm{PB}$ and $\mathrm{CF}$. This also shows that height on the shore did not affect the response of the alga to transplantation.

Secondly, many studies have shown that animals and plants are capable of unique responses to changes in physical (Scheiner \& Goodnight 1984, Schmitt 1993, Dudley 1996, Relyea \& Werner 2000) and biological (Bertness et al. 1998, Raimondi et al. 2000, Agrawal 2001) variables, suggesting that phenotypic plasticity is pervasive in natural populations. In marine algae, experimental analyses of causes of morphological changes have focused mainly on effects of herbivores (e.g. Lewis et al. 1987), whereas population-specific responses to changes in abiotic conditions have been inferred mostly from comparisons of contrasting habitats and in the laboratory (e.g. de Senerpont Domis et al. 2003). Our study adds to a limited number of investigations showing that phenotypic differences in a marine alga can be reversed by changes in environmental conditions, using a field-based transplant experiment (see also Blanchette 1997 and Serisawa et al. 2002). Despite the asymmetry in our results, the data clearly showed that the larger size and biomass of individual fronds of Rissoella verruculosa at PB was a reversible feature of this population that depended on local environmental conditions.

Several physical and/or biological processes might account for differences in size of Rissoella verruculosa between PB and CF. Some studies have shown experimentally that wave exposure can affect the size of macroalgae (e.g. Blanchette 1997). This variable was, however, unlikely to account for the outcome of our transplantation experiment, since both $\mathrm{PB}$ and $\mathrm{CF}$ were exposed to waves (though exposure was measured subjectively in this study). Other processes that might account for spatial variability in morphology of $R$. verruculosa were differences in local oceanography between locations. Indeed, PB is located in a more productive region of the northwest Mediterranean compared to CF (Estrada et al. 1985) and this might explain the larger size of $R$. verruculosa at the northern location. Testing this explanatory model would require transplantation experiments at replicated locations within each region, possibly coupled with the direct manipulation of nutrients. Such experiments are already underway.
The asymmetrical response of populations to changes in environmental conditions, as investigated in reciprocal transplant experiments, is not unique to our study. Crowe \& Underwood (1999), for example, used a reciprocal transplant experiment to investigate differences in rates of dispersal of an intertidal gastropod between mangrove forests and rocky shores. These authors found that snails taken to rocky shores from mangrove forests exhibited increased dispersal, while the reverse was not true. These findings suggest that asymmetries in responses of populations to changes in local conditions may be more common than previously thought. This calls for more experimental tests of hypotheses on causes of morphological or behavioural variation between populations living in contrasting habitats, with appropriate experimental protocols and procedural controls for artefacts like those employed by Chapman (1986) and by Crowe \& Underwood (1999).

Why did differences in size and biomass between populations not generate large-scale patterns in cover? The most sensible explanation, given the results, was density-dependent regulation. The alga had larger fronds at $\mathrm{PB}$ than $\mathrm{CF}$, but density exhibited exactly the opposite pattern, so that the number of upright fronds per unit of area was inversely related to size. This type of density-dependent relationship resulted in similar patterns of cover at the 2 locations (Menconi et al. 1999, Benedetti-Cecchi 2001). In contrast, the ability of Rissoella verruculosa to develop larger fronds at PB than at $\mathrm{CF}$, coupled with a lack of large-scale differences in percentage cover, translated into regional patterns of productivity, as shown by data on biomass.

The prevalence of density-dependent over densityindependent mechanisms of regulation has been widely debated in the ecological literature (Andrewartha \& Birch 1984, Turchin 1999). Although both conditions can be important depending on context, studies have indicated that traits such as survivorship and growth of populations are generally reduced at large densities (e.g. Altwegg 2003). Understanding the influence of density-dependent processes on populations may, however, require more than the analysis of pair-wise comparisons between density and other traits of populations. Our results indicated similar negative relationships between density and size and between density and biomass of Rissoella verruculosa, but there was no apparent relationship between density and cover. It is because density and cover were uncoupled that a large-scale pattern of productivity was evident in our study. This could not be easily predicted from separate comparisons between density and the other traits of $R$. verruculosa.

Description of pattern over multiple scales in space and time is a prerequisite for understanding causal processes. Focusing on single attributes of populations, 
however, may not be sufficient to appreciate the full range of processes to which populations may respond. An analysis of spatial pattern restricted to mean percentage cover would not have revealed the sensitivity of Rissoella verruculosa to large-scale processes. Morphological plasticity made it possible for this alga to display different patterns in size, biomass and density between locations and to accommodate its growth and productivity to local conditions when transplanted from PB to CF. Despite the presence of density-dependent mechanisms of regulation of size and biomass, cover of $R$. verruculosa was unrelated to either trait so that patterns in size translated into regional patterns of productivity. Only by examining the relationship between density and each of the other attributes of $R$. verruculosa simultaneously, could these effects be uncovered. This further emphasized the advantages of comparing variation of several attributes of populations in order to understand linkages between pattern and process across scales.

Acknowledgements. We thank T. Crowe, F. Micheli and the anonymous reviewers for helpful comments on the manuscript and T. Underwood who assisted with the analysis and interpretation of the reciprocal transplant experiment early in the project. We also thank the numerous people that have assisted with the field work and special thanks go to M. Menconi for his dedication, inspiration and invaluable advice during the early stages of this work. This research was supported by various grants from the University of Pisa.

\section{LITERATURE CITED}

Åberg P, Pavia H (1997) Temporal and multiple scale spatial variation in juvenile and adult abundance of the brown alga Ascophyllum nodosum. Mar Ecol Prog Ser 158: 111-119

Agrawal AA (2001) Phenotipic plasticity in the interactions and evolution of species. Science 294:321-326

Altwegg R (2003) Multistage density dependence in an amphibian. Oecologia 136:46-50

Andrewartha HG, Birch LC (1984) The ecological web. University of Chicago Press, Chicago, IL

Benedetti-Cecchi L (2000) Predicting direct and indirect effects during succession in a midlittoral rocky shore assemblage. Ecol Monogr 70:45-72

Benedetti-Cecchi L (2001) Variability in abundance of algae and invertebrates at different spatial scales on rocky sea shores. Mar Ecol Prog Ser 215:79-92

Bertness MD, Callaway R (1994) Positive interactions in communities. Trends Ecol Evol 9:191-193

Bertness MD, Leonard GH (1997) The role of positive interactions in communities: lessons from intertidal habitats. Ecology 78:1976-1989

Bertness MD, Gaines SD, Yeh SM (1998) Making mountains out of barnacles: the dynamics of acorn barnacle hummocking. Ecology 79:1382-1394

Blanchette CA (1997) Size and survival of intertidal plants in response to wave action: a case study with Fucus gardneri. Ecology 78:1563-1578
Carpenter SR (1990) Large-scale perturbations: opportunities for innovation. Ecology 71:2038-2043

Carpenter SR, Chisholm SW, Krebs CJ, Schindler DW, Wright RF (1995) Ecosystem experiments. Science 269:324-327

Chapman MG (1986) Assessment of some controls in experimental transplants of intertidal gastropods. J Exp Mar Biol Ecol 103:181-201

Connolly SR, Roughgarden J (1998) Theory of marine communities: competition, predation, and recruitmentdependent interaction strength. Ecol Monogr 69:277-296

Crawley MJ, Harral JE (2001) Scale dependence in plant biodiversity. Science 291:864-868

Crowe TP, Underwood AJ (1999) Differences in dispersal of an intertidal gastropod in two habitats: the need for and design of repeated experimental transplantation. J Exp Mar Biol Ecol 237:31-60

Dayton PK, Tegner MJ (1984) The importance of scale in community ecology: a kelp forest example with terrestrial analogs. In: Price PW, Slobodchikoff CN, Gand WS (eds) A new ecology: novel approaches to interactive systems. John Wiley \& Sons, New York, p 457-481

de Senerpont Domis LN, Famà P, Bartlett AJ, Prud'homme van Reine WF, Armenta Espinosa C, Trono GC (2003) Defining taxon boundaries in members of the morphologically and genetically plastic genus Caulerpa (Caulerpales, Chlorophyta). J Phycol 39:1019-1037

Dudley SA (1996) The response to differing selection on plant physiological traits: evidence for local adaptation. Evolution 50:103-110

Estrada M, Vives F, Alcarez M (1985) Life and the productivity of the open sea. In: Margalef R (ed) Western Mediterranean. Pergamon Press, Oxford, p 148-197

Farnsworth EJ, Ellison AM (1996) Scale-dependent spatial and temporal variability in biogeography of mangrove root epibiont communities. Ecol Monogr 66:45-66

Fowler-Walker MG, Connell SD (2002) Opposing states of subtidal habitat across temperate Australia: consistency and predictability in kelp canopy-benthic associations. Mar Ecol Prog Ser 240:49-56

Gaston KJ, McArdle BH (1993) Measurement of variation in the size of populations in space and time: some points of clarification. Oikos 68:357-360

Hewitt JE, Thrush SF, Cummings VJ, Turner SJ (1998) The effect of changing sampling scales on our ability to detect effects of large-scale processes on communities. J Exp Mar Biol Ecol 227:251-264

Holling CS (1992) Cross-scale morphology, geometry, and dynamics of ecosystems. Ecol Monogr 62:447-502

Hughes TP, Baird AH, Dinsdale EA, Moltschaniwskyj NA, Pretchett MS, Tanner JE, Willis BL (1999) Patterns of recruitment and abundance of corals along the Great Barrier Reef. Nature 397:59-63

Jenkins SR, Åberg P, Cervin G, Coleman RA and 9 others (2000) Spatial and temporal variation in settlement and recruitment of the intertidal barnacle Semibalanus balanoides (L.) (Crustacea: Cirripedia) over a European scale. J Exp Mar Biol Ecol 243:209-225

Kotliar NB, Wiens JA (1990) Multiple scales of patchiness and patch structure: a hierarchical framework for the study of heterogeneity. Oikos 59:253-260

Levin SA (1992) The problem of pattern and scale in ecology. Ecology 73:1943-1967

Lewis SM, Norris JN, Searles RB (1987) The regulation of morphological plasticity in tropical reef algae by herbivory. Ecology 68:636-641

Menconi M, Benedetti-Cecchi L, Cinelli F (1999) Spatial and temporal variability in the distribution of algae and inver- 
tebrates on rocky shores in the northwest Mediterranean. J Exp Mar Biol Ecol 233:1-23

Menge BA, Olson AM (1990) Role of scale and environmental factors in regulation of community structure. Trends Ecol Evol 5:52-57

Raimondi PT, Forde SE, Delph LF, Lively CM (2000) Processes structuring communities: Evidence from trait-mediated indirect effects through induced polymorphisms. Oikos 91:353-361

Relyea RA, Werner EE (2000) Morphological plasticity in four larval anurans distributed along an environmental gradient. Copeia 1:178-190

Sale PF (1998) Appropriate spatial scales for studies of reeffish ecology. Aust J Ecol 23:202-208

Scheiner SM, Goodnight CJ (1984) The comparison of phenotypic plasticity and genetic variation in populations of the grass Danthonia spicata. Evolution 38:845-855

Schmitt J (1993) Reaction norms of morphological and lifehistory traits to light availability in Impatines capensis. Evolution 47:1654-1668

Schneider DC (1994) Quantitative ecology: spatial and temporal scaling. Academic Press, San Diego, CA

Serisawa Y, Yokohama Y, Aruga Y, Tanaka J (2002) Growth of Ecklonia cava (Laminarilaes, Phaeophyta) sporophytes

Editorial responsibility: Roger Hughes (Contributing Editor), Bangor, UK transplanted to a locality with different temperature conditions. Phycol Res 50:201-207

Turchin P (1999) Population regulation: a synthetic view. Oikos 84:153-159

Underwood AJ (1990) Experiments in ecology and management: their logics, functions and interpretations. Aust J Ecol 15:365-389

Underwood AJ (1997) Experiments in ecology. Their logical design and interpretation using analysis of variance. Cambridge University Press, Cambridge

Underwood AJ, Chapman MG (1996) Scales of spatial patterns of distribution of intertidal invertebrates. Oecologia 107:212-224

Underwood AJ, Chapman MG, Crowe TP (2004) Identifying and understanding ecological preferences for habitat of prey. J Exp Mar Biol Ecol 300:161-187

Wiens JA, Stenseth NC, Van Horne B, Ims RA (1993) Ecological mechanisms and landscape ecology. Oikos 66: 369-380

Winer BJ, Brown DR, Michelis KM (1991) Statistical principles in experimental design, 3rd edn. McGraw-Hill, New York

Wu J, Loucks OL (1995) From balance of nature to hierarchical patch dynamics: a paradigm shift in ecology. Q Rev Biol 70:439-466

Submitted: May 9, 2005; Accepted: October 18, 2005

Proofs received from author(s): May 15, 2006 